\title{
Ambient vibration recording on the Maddalena Bridge in Borgo a Mozzano (Italy): data analysis
}

\author{
Riccardo M. Azzara ${ }^{1, *}$, Anna De Falco ${ }^{2}$, Maria Girardi ${ }^{3}$, Daniele Pellegrini ${ }^{3}$ \\ ${ }^{1}$ Istituto Nazionale di Geofisica e Vulcanologia, Osservatorio Sismologico di Arezzo, Italy \\ 2 Department of Energy, Systems, Territory and Constructions Engineering, University of Pisa, Italy \\ 3 Institute of Information Science and Technologies "A. Faedo", ISTI-CNR, Pisa, Italy
}

\author{
Article history \\ Received August 1, 2016; accepted May 16, 2017. \\ Subject classification: \\ Ambient vibrations, Seismic monitoring, Structural dynamic response, Operational Modal Analysis.
}

\begin{abstract}
This paper reports on a vibration measurements campaign performed on the medieval Maddalena Bridge, also known as the "Devil's Bridge", in Borgo a Mozzano (Italy), one of the most fascinating in Italy. This $11^{\text {th }}$ century masonry bridge, supported by four circular arcades, crosses the Serchio River for about one hundred meters. Information on the dynamic response of the structure have been obtained through a wholly nondestructive technique, by measuring the environmental vibrations affecting the structures. A monitoring system has been fitted on the external surface of the bridge in order to evaluate its dynamic response to vibrations originating in the adjacent railway and two nearby roads. The natural frequencies and mode shapes of the structure and the corresponding damping ratios have been obtained by analyzing the recorded data using different techniques of Operational Modal Analysis. Lastly, a finite-element model of the bridge has been calibrated to fit the experimental data.
\end{abstract}

\section{Introduction}

Nowadays, performing vibration measurements has become one of the most widely used non-destructive techniques for assessing the structural health of ancient masonry constructions. This technique provides a simple and effective way to obtain information on the dynamic behavior of a construction and thereby investigate its safety level. Moreover, when the experimental data are coupled with a finite-element model, an estimate of the mechanical properties of the constituent materials can also be obtained via suitable model updating procedures.

Recently, many authors have devoted considerable attention to the dynamic assessment of ancient masonry bridges [Aoki et al. 2007, Bayraktar et al. 2009, Bayraktar et al. 2015, Boscato et al. 2010, Giof- fré et al. 2008, Perez-Garcia et al. 2011, Sevim et al. 2011]. In this context, the present paper reports on a vibration measurement campaign on the Maddalena Bridge, also known as "Ponte del Diavolo", in Borgo a Mozzano, near Lucca (Figure 1). The purpose of the study is to obtain information on the dynamic characteristics of this fascinating historic structure.

As for the method used, there exist two main kinds of modal testing: EMA (Experimental Modal Analysis), which uses controlled input forces, and OMA (Operational Modal Analysis), which uses ambient vibrations [Brincker and Ventura, 2015]. Both methods have been employed in the past and are capable of determining the dynamic characteristics of a structure. The main advantage of forced vibration over in-operation vibration is that the former enables the level of excitation and induced vibration to be carefully controlled, while the latter type of measurement relies on natural forces, such as wind, and/or uncontrolled artificial forces (i.e., traffic or micro-tremors) to excite the structure, sometimes at very low levels of vibration. For this reason, the sensitivity of sensors used for OMA measurements is generally much higher than those required for forced vibration tests. This is particularly true for masonry structures, whose vibrations are generally very low in amplitude. In general, the experimental set-up of a forced vibration test is a complex task, especially for large, massive structures, such as masonry constructions, and often requires interruption of the structure's normal function, such as traffic shutdowns in the case of a bridge. In addition, the installation of artificial force sources on ancient buildings is a delicate operation, often involving oversight by heritage conservation authorities. For these 


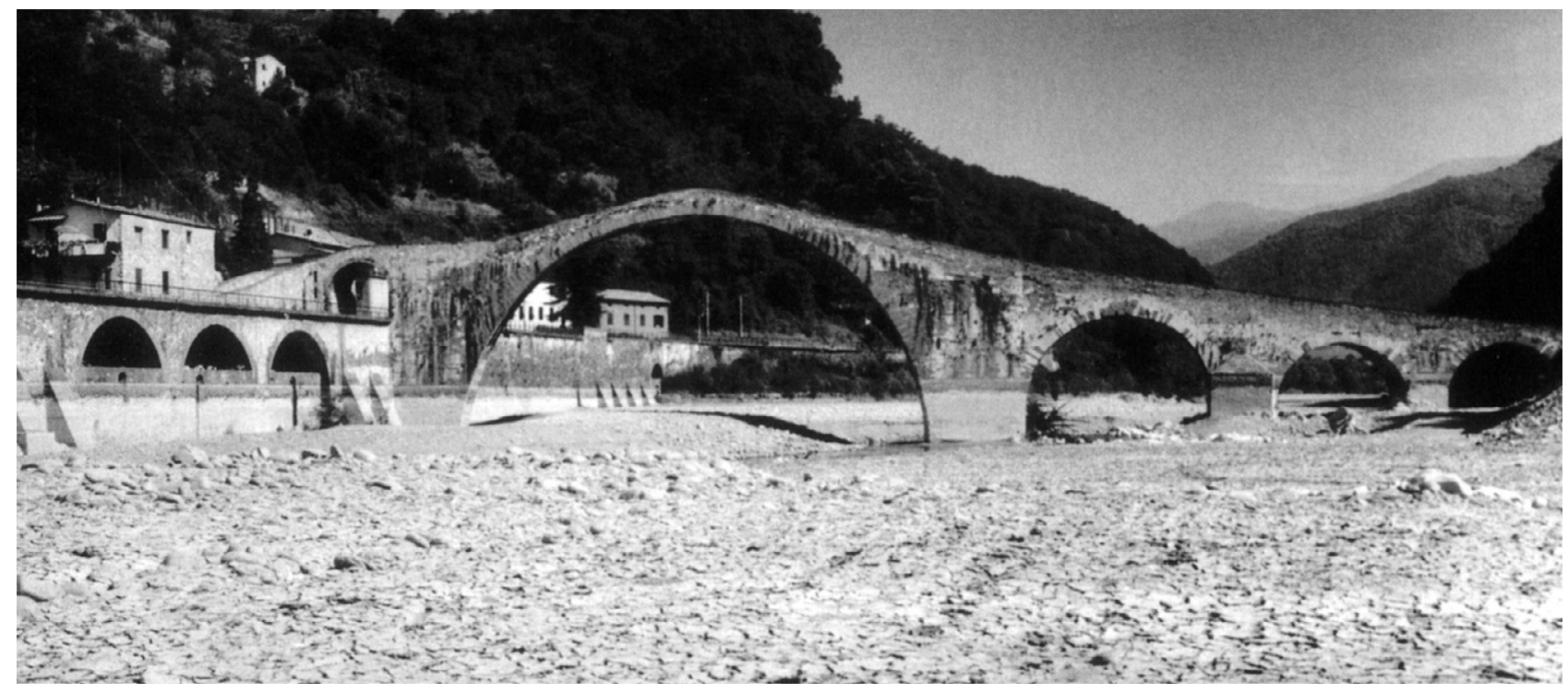

Figure 1. The Maddalena Bridge and adjacent railway.

reasons, and thanks to the availability of ever-more sensitive instrumentation, the use of OMA techniques for testing the dynamic behavior of ancient masonry structures has assumed an increasing important role among researchers and technicians.

OMA testing generates a considerable amount of data, the analysis of which is generally a very complex task. In practice, the input excitation needs not be measured, under the assumption that it does not contain any specific information, i.e. the input can be modeled approximately as white noise. Since the forcing function is unknown, the frequency response functions between the force and the response signals cannot be calculated. Instead, the analysis relies on correlation functions and spectral density functions estimated on the structural responses. In addition, since the apparatus for OMA testing is generally expensive, a limited number of sensors are used and some of these sensors are moved over the structure to obtain several data sets. In order to be able to assemble mode shapes using the different data sets, some reference sensors are kept in the same position during all tests, while the remaining sensors are moved progressively over the structure.

The experimental campaign on the Maddalena Bridge was conducted using the OMA technique. The following paper details the data analysis procedure adopted. In particular, the velocities recorded on the bridge have been processed via different methods: the Covariance-driven Stochastic Subspace Identification (SSI/Cov) method, implemented in the MACEC code [Reynders et al. 2014], and the Enhanced Frequency Domain Decomposition method [Batel 2002), implemented in TruDI [Pellegrini 2015]. The bridge's struc- ture has been discretized into three-dimensional finite elements via the NOSA-ITACA code [Binante et al., 2017]. The mechanical characteristics of the bridge's constituent material and boundary conditions have been calibrated to fit the experimental data.

\section{The Maddalena Bridge}

Also known as the Devil's Bridge, this famous, fascinating structure is the only example now remaining of the numerous bridges which once spanned the Serchio River (Figure 1). It can be dated back to around the $11^{\text {th }}$ century and, for many decades, it served as a road infrastructure of fundamental importance, as it was situated at the center of the main trade routes traversing the Italian territory.

The stone masonry construction crosses the Serchio River for a total length of about one hundred meters, following the path of rocky outcrops, and deviating over fifteen degrees from the direction perpendicular to the river. It consists of one large arch of $38 \mathrm{~m}$ in span and three arches on the left-hand side, the first from the main arch having a span of $14.5 \mathrm{~m}$, the second of $10.5 \mathrm{~m}$, and the third of $8.5 \mathrm{~m}$. The main arch, which is just one meter high at the key, has a perfectly circular intrados profile and springs directly from the rock forming the riverbed. The transverse section of the bridge ranges between $3.5 \mathrm{~m}$ and $3.7 \mathrm{~m}$. In order to ensure that such a slender structure could withstand the force of the (over $10 \mathrm{~m}$ deep) onrushing waters, the upstream cutwaters of the three piers were fashioned with a peculiar raking angle, while the downstream pier between the second and third arch was reinforced with a trapezoidal buttress (Figure 2).

The single arch, about $5 \mathrm{~m}$ in span, on the right 


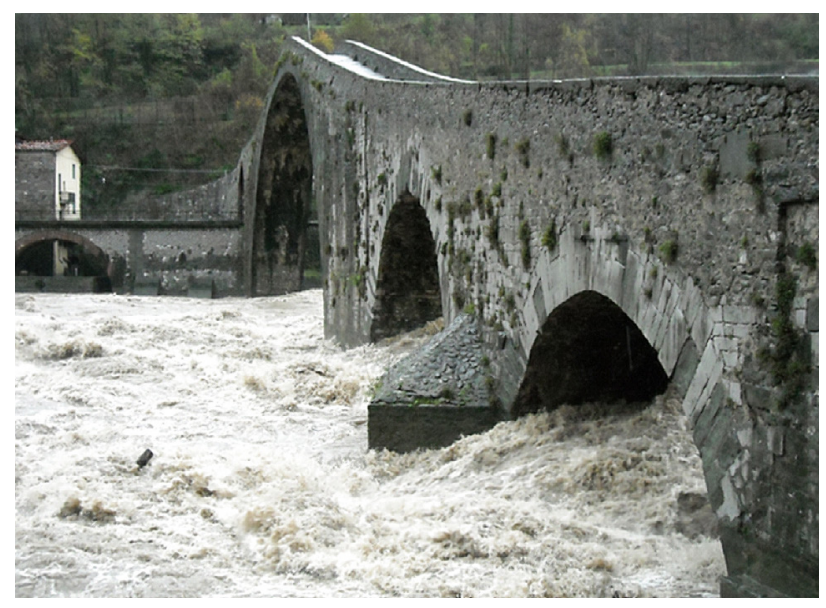

Figure 2. The Serchio River in full spate, from the downstream side.

abutment allows the passage of the railway, which was constructed in the late $19^{\text {th }}$ century in order to connect Lucca with the Emilia Romagna region. At that time the bridge's abutment was partially demolished in order to make way for the new infrastructure, and an S-shaped ramp was built on the right bank.

The shape of the bridge imparts to the roadway an inclination which was too steep even for the passage of old wheeled carriages [Weale et al. 1843]. Due to its steepness, narrowness and the angle formed in the roadway at the wing walls, the bridge has been threatened with demolition several times in the past. Eventually, a new ramp added near the railway made the bridge permanently inaccessible to vehicles, but the great fascination evoked by the bridge and relatively recent attitudes towards conservation have spared it from demolition.

The main kinds of stone used in the bridge's construction are, for the greatest part, a particular variety of sandstone (Macigno sandstone) and, to a lesser extent, a blue limestone. The quoins of the smaller arches and all the voussoirs of the large arch are built from carefully dressed stones with tight uniform joints (Figure 3). The stone courses in the large arch vary from $0.2 \mathrm{~m}$ to $0.6 \mathrm{~m}$ deep. The outer rocks were dressed to a rather uniform surface and even faced at the foundations of the large central pier (Figure 4). Over the centuries the bridge has undergone some repairs, mostly about the parapets, coping, wings and roadway; this is the reason why the masonry texture has become somewhere irregular.

After 1950, a barrier was built for the Vinchiana hydraulic power plant $6 \mathrm{~km}$ downstream in the Serchio River and now the bridge is reflected in the waters of the reservoir, whose depth reaches about $5 \mathrm{~m}$ at the central pier.

Currently there are several lines of communica-
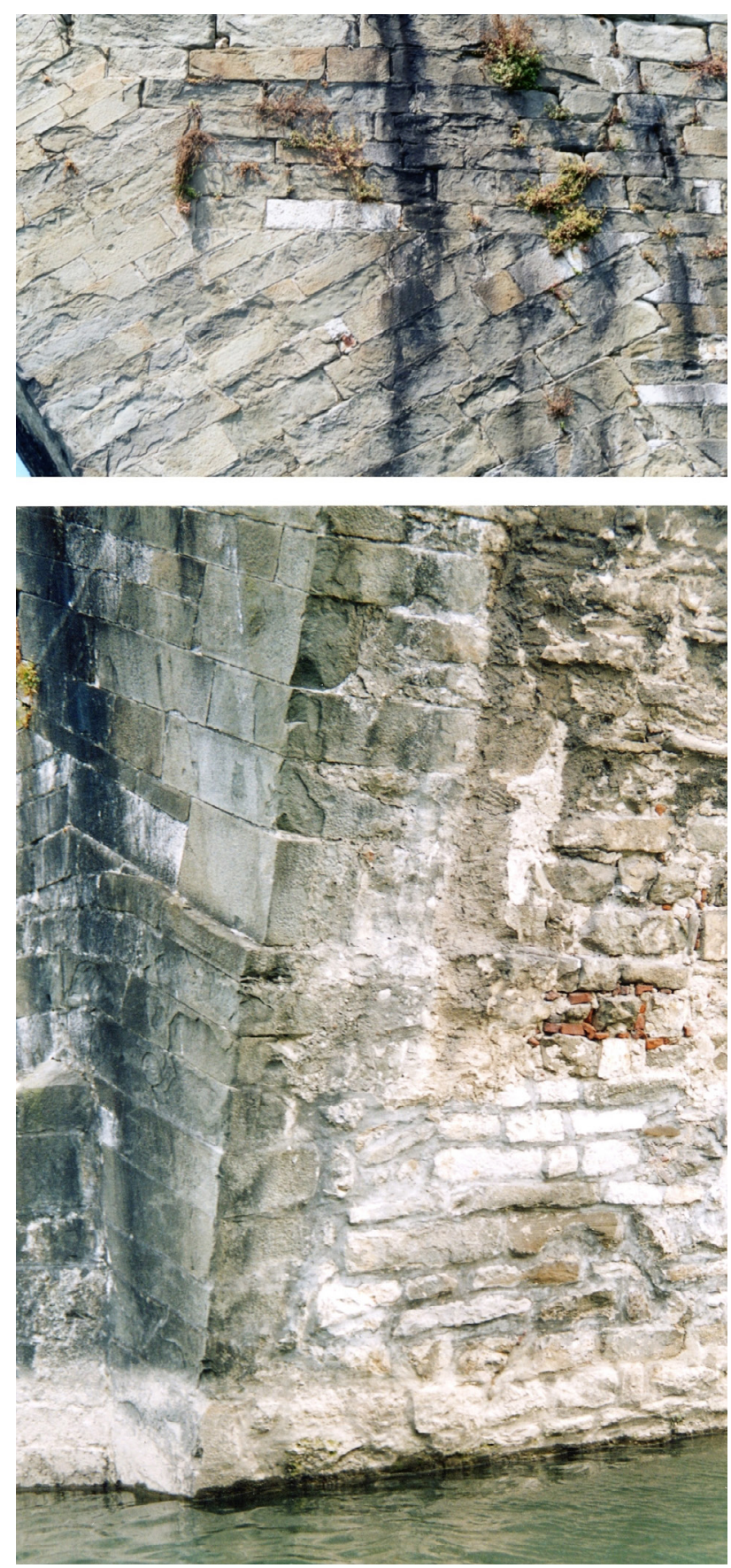

Figure 3. Detail of the masonry texture on the main arch: at the left haunch on the downstream side (top) and at the left springer on the upstream side (bottom).

tion close to the bridge: in addition to the railway, two heavily trafficked thoroughfares run along the banks of the Serchio River on both sides and transmit the road vibrations to the old bridge's structure.

A detailed historical review of the bridge and the stages of its construction over time have been carried out by [Gucci and De Falco 2010], and a finite-element model aimed at studying its static and dynamic behavior has been proposed by [De Falco et al. 2014].

In 2006 a first expeditious experimental campaign [Gucci and De Falco 2010], mainly aimed at recording 


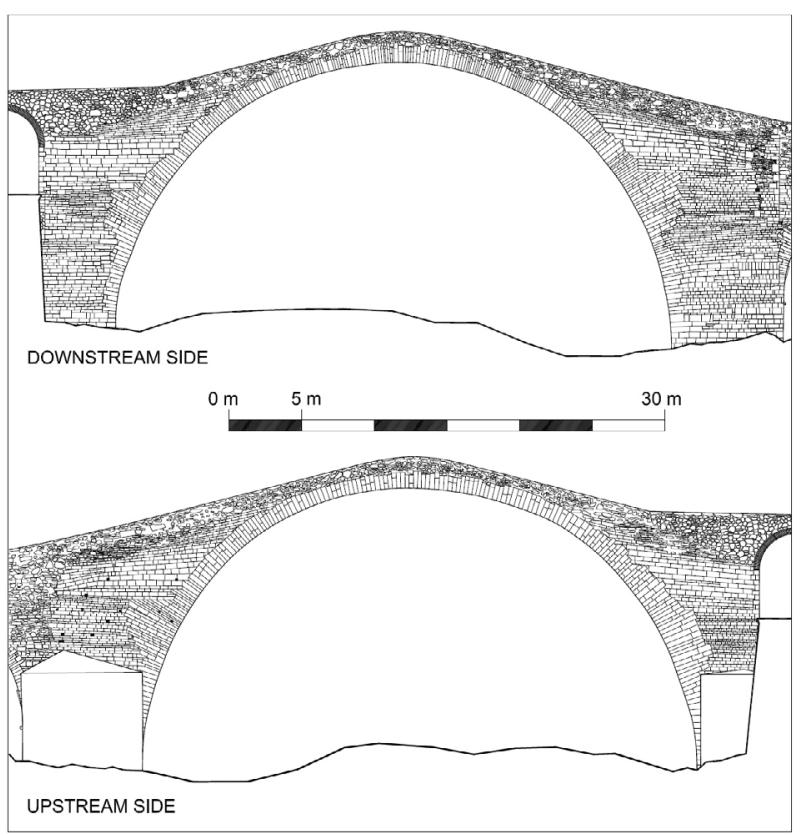

Figure 4. Masonry texture on the main arch from both downstream and upstream sides.

the vibrations induced on the bridge by the adjacent railway, was performed. The present study reports on the results of a new monitoring experiment conducted in 2015 [Azzara, De Falco et al. 2016].

\section{The experimental campaign}

The Maddalena Bridge was instrumented with four SARA three-axial seismometric stations. Each station contains a SL06 24-bit digitizer coupled to a SS20 seismometer (electrodynamic velocity transducer, henceforth, sensor). A sampling frequency of $100 \mathrm{~Hz}$ was chosen to acquire the structure's response to ambient excitation. These instruments, usually employed for seismic monitoring networks, have been made available by the Seismologic Observatory of Arezzo (INGV) and have been used for previous studies of the Asinelli and Garisenda towers in Bologna [Azzara et al. 2014] and the San Frediano bell tower in Lucca [Azzara, De Roeck et al. 2016].

Figure 5 shows a seismometric station on the bridge road surface (Test 1 ). Five tests were performed with the four sensors fitted in different arrangements throughout the bridge. Figure 6 illustrates the scheme of the tests: the six locations (sections) equipped with seismometric stations are marked with capital letters in alphabetical order, from A to F. In particular, for Test 1 the main arch was fitted with sensors 3 and 4 , both positioned at section $\mathrm{C}$, in order to capture any torsional behavior of the bridge. For Test 2, sensor 1 remained fixed in the same position as in the first test, while the other three were shifted toward the right

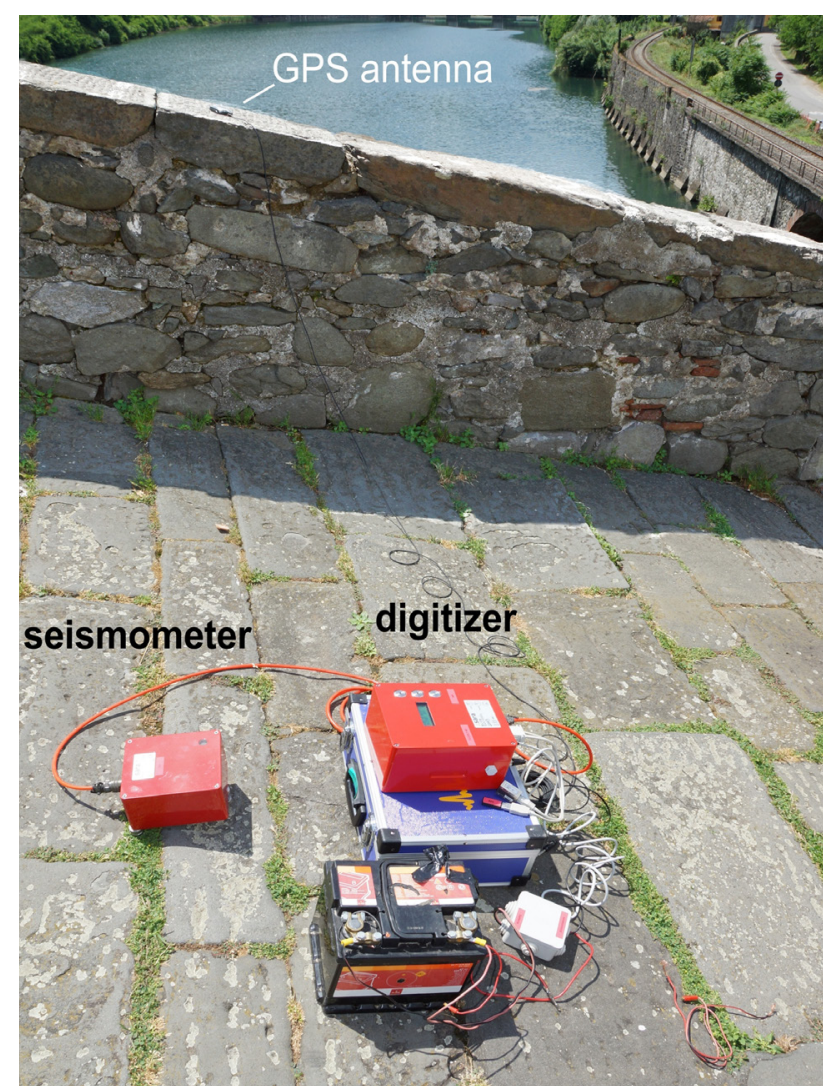

Figure 5. Seismometric station on the bridge road surface during Test 1 .

abutment. Then in Test 3, all sensors were moved in the transverse direction from the road surface to the parapet walls. It was thought that this particular configuration would provide information on the dynamic behavior of the parapet walls. Finally, in Tests 4 and 5 the stations were once again arranged on the bridge road surface, though shifted toward the left abutment. Sensor 1 was the reference instrument during the tests. The minimum duration of the recordings for each test was thirty minutes. The acceleration values induced by the surrounding environment, adjacent roads, wind, etc., obtained via the recorded velocities, are on the order of $2 \cdot 10^{-3} \mathrm{~m} / \mathrm{s}^{2}$, whereas the peak acceleration on the bridge induced by the passage of the local train at 15:22 GMT is about $7 \cdot 10^{-3} \mathrm{~m} / \mathrm{s}^{2}$.

\section{Data analysis}

\subsection{Preliminary data treatment}

A preliminary analysis of experimental data was performed by analyzing the single signals recorded during the tests. Then, the first part of each record was canceled (about 300 s) and the remaining data divided into shorter signals, each lasting $300 \mathrm{~s}$. All results presented in the following have been first calculated on these short signals and then averaged in order to 
TEST 1

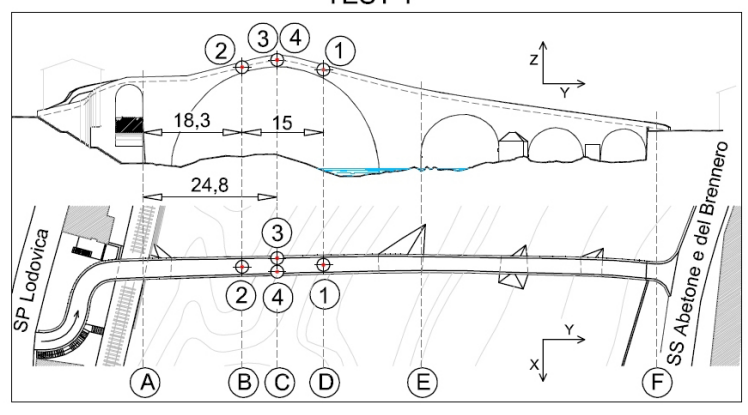

TEST 2

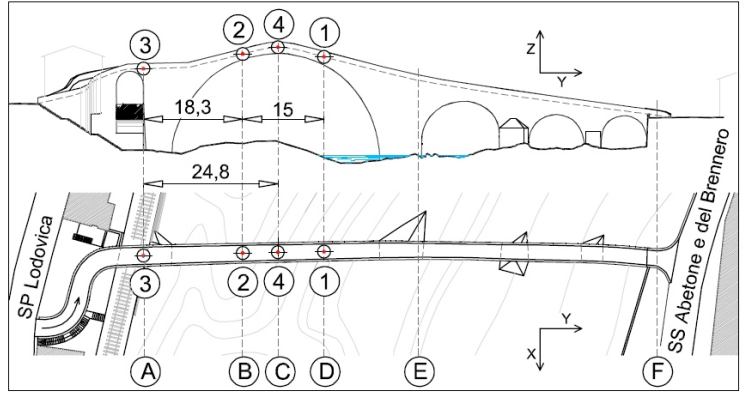

TEST 3

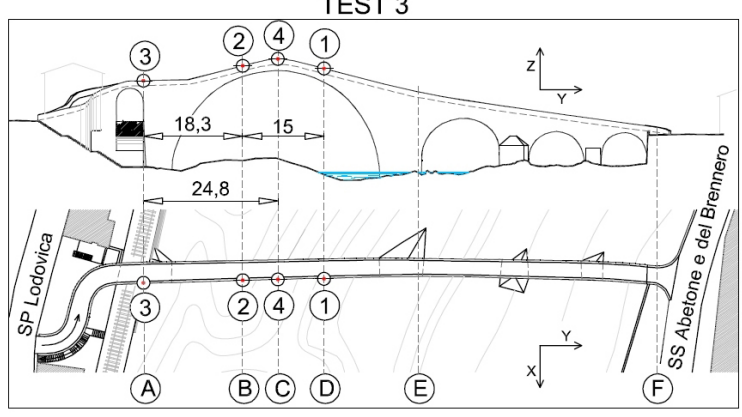

TEST 4

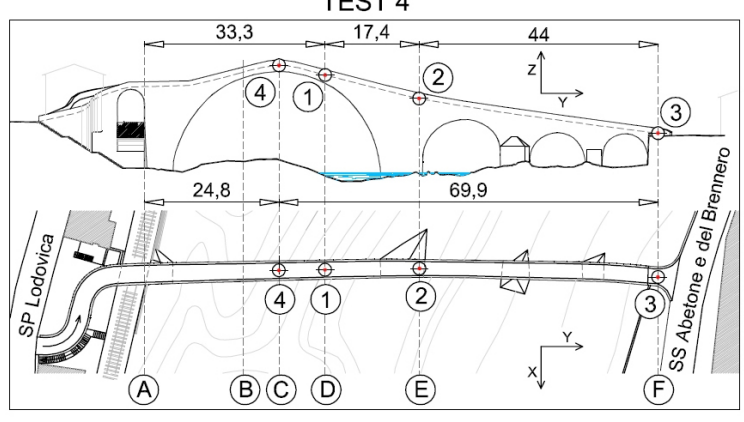

TEST 5

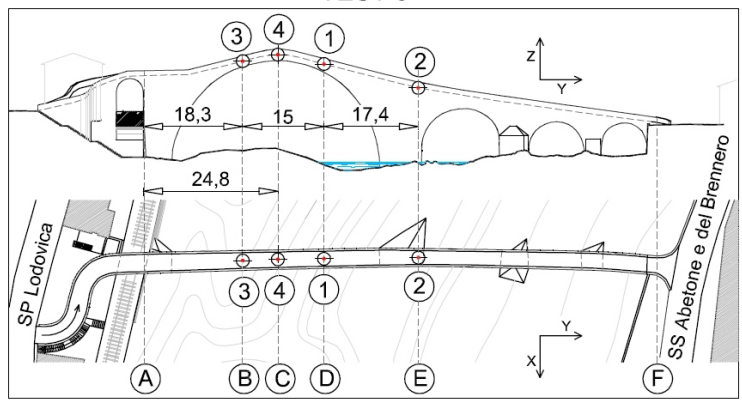

Figure 6. Sensor arrangement for each of the experimental tests.

remove transient phenomena.

A fast method for estimating modal parameters from OMA tests is the rather simple "peak-picking", or
Basic Frequency Domain technique. This technique relies on the fact that when a structure is subjected to ambient excitations, its frequency response is stronger near its natural frequencies. These frequencies can be identified from the peaks in the power spectral densities (PSD) or in the spectral amplitudes computed for the sensors' recordings. Figure 7 shows a semi-log plot of the spectral amplitudes of the signals recorded in the sections from A to D. The black line represents the signal of road surface sensors (Test 2), and the blue line represents the signal recorded on the parapet walls (Test 3). Some peaks are clearly evident. In particular, all sensors recorded a dominant frequency around $3.3 \mathrm{~Hz}$, which is noticeably directed in an out-of-plane $(x)$ direction, though they do exhibit a component along $z$, probably due to torsional movements. Other peaks are evident around $5 \mathrm{~Hz}$, clearly visible in the three directions and particularly highlighted in Section C, as well as around $7 \mathrm{~Hz}$. These frequencies exhibit the highest spectral amplitude values in the $y$ and $z$ directions and seem to represent a mainly in-plane motion of the bridge. Other peaks can be detected at around $9 \mathrm{~Hz}$ and $13 \mathrm{~Hz}$. Test 3 , which was performed after moving all sensors onto the parapets, has been analyzed separately in the figure and its spectral amplitudes are shown in blue. For low frequencies, below $10 \mathrm{~Hz}$, the parapets' behavior is substantially superposed on that of the bridge (black line). However, at higher frequencies (around $17 \mathrm{~Hz}$ ) some differences emerge, and are particularly evident in the $\mathrm{x}$ direction. These can be interpreted as out-of-plane movements of the parapet, as will be explained later. Moreover, a peak at $25 \mathrm{~Hz}$ in the $x$ direction is clearly visible in the signal recorded in section A on the parapet. This frequency, which is not recognizable in the body of the bridge (Test 2), may however be induced by the peculiar geometry of section $\mathrm{A}$, which is situated near the railway arcade and the bridge's end ramp.

For Test 1, Section C was fitted with two instruments (sensors 3 and 4) in order to capture any torsional movements of the bridge.

Figure 8 shows the spectral amplitudes of the sum (blue line) and the difference (red line) of the signals recorded by sensors 3 and 4 along the $z$ direction. The spectral amplitude of the differences between the $z$ components shows torsional movements in all the identified frequencies, particularly evident at 3.3. Hz. A very strong in-phase component along $z$ at about $5 \mathrm{~Hz}$ reveals in-plane motion of the midsection of the bridge's main arch. 

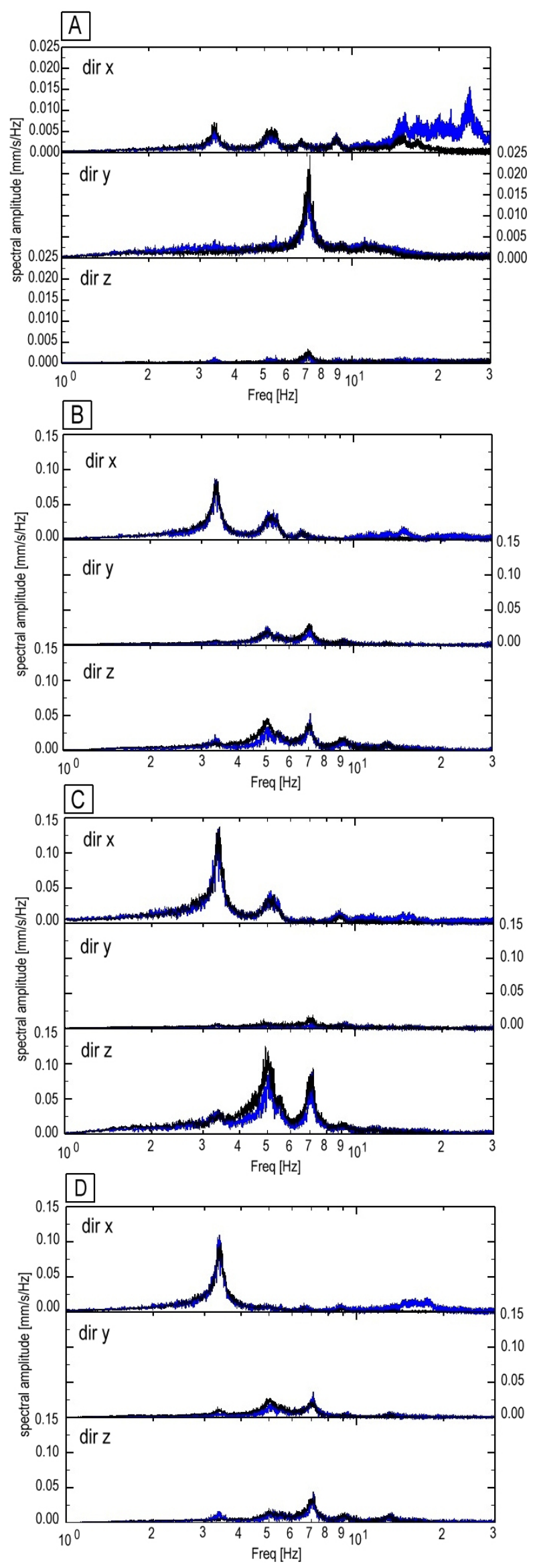

Figure 7. Semi-log plot of the spectral amplitudes of signals recorded in sections A to D from Test 2 (black line) with sensors on the road surface, and from Test 3 (blue line) with sensors on the downstream parapet wall.
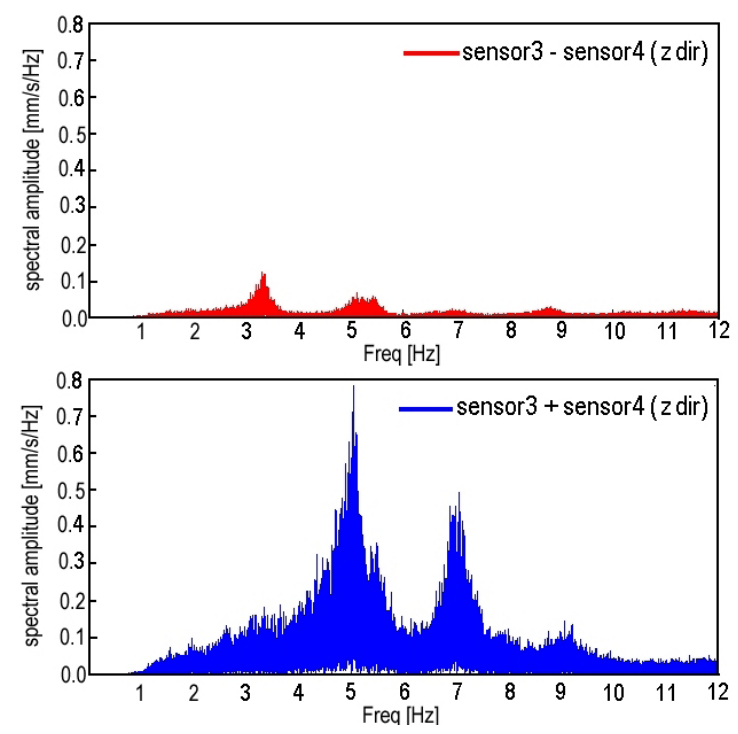

Figure 8. Spectral amplitudes of the sum (blue line) and the difference (red line) of the signals recorded along the $z$ direction in section $\mathrm{C}$ by stations 3 and 4 during Test 1 .

\subsection{Algorithms for Operational Modal Analysis}

The preliminary analyses shown in the previous section allowed us to identify some of the bridge's natural frequencies and to roughly identify the corresponding mode shapes. However, more robust techniques available in literature enable us to automatically process all the data from the sensors installed on the structure.

The time signals measured via ambient vibration tests can be processed both in the time domain or the frequency domain.

Bricker et al [2001] and Batel [2002] presented an extension of the simple Basic Frequency Domain method, known as the Enhanced Frequency Domain Decomposition (EFDD) method. For a given set of output signals (channels) recorded on the structure, this method makes use of the spectral density matrices $\mathbf{G}_{y y}(\omega)$ [Azzara, De Falco et al. 2016], computed on the output signals, and of their singular value decomposition,

$$
\mathbf{G}_{y y}(\omega)=[\boldsymbol{\Phi}][\Sigma][\boldsymbol{\Phi}]^{\mathrm{H}}, \quad[\boldsymbol{\Phi}][\boldsymbol{\Phi}]^{\mathrm{H}}=[1]
$$

In Equation (1) the subscript $y$ refers to the output, and $\omega$ represents the frequency. The superscript $\mathrm{H}$ denotes a Hermitian transformation, matrices $\sum$ are, for each, real-value diagonal matrices, whose non-zero diagonal terms $\left(s_{1}(\omega)>s_{2}(\omega)>\ldots>s_{m}(\omega)\right)$ are called singular values. There are as many singular values as the channels measured. In particular, the first curve $s_{1}(\omega)$ shows resonant peaks corresponding to the structure's natural frequencies. If only one mode dominates at a 
particular frequency, then only curve $s_{1}(\omega)$ will show a local maximum at that frequency. On the contrary, in the case of close or repeated modes, more than one singular values curve will show resonant peaks. Matrices $[\Phi]=\left\{\Phi_{1}, \ldots, \Phi_{m}\right\}$, in turn, provide an estimate of the unscaled structural modal shapes, whose components are computed along each direction. The portions of curve $s_{1}(\omega)$ around the peaks can be converted to the time-domain through the Inverse Discrete Fourier Transform and furnish an estimate of the corresponding damping ratio for each mode [Brincker et al. 2001]. Numerous codes have been formulated to implement the EFDD method [Brincker and Ventura, 2015]. In this paper we will make use of TruDI, a numerical procedure implemented by one of the authors [Pellegrini 2015].

In contrast to the FDD techniques, Stochastic Subspace Identification methods work in the time domain. In particular, the MACEC code [Reynders et al. 2014], in which the Covariance-driven Stochastic Subspace Identification (SSI/Cov) method is implemented, will be used in the following to analyze the bridge's data, together with TruDI.

Under the hypothesis of white noise for the input data and instrumental errors, the SSI/Cov method is based on the following state-space model, which, after discretization in time, describes a linear time-invariant system:

$$
\begin{gathered}
\mathbf{x}_{k+1}=\mathbf{A} \mathbf{x}_{k}+\mathbf{w}_{k} \\
\mathbf{y}_{k}=\mathbf{C} \mathbf{x}_{k}+\mathbf{v}_{k}
\end{gathered}
$$

In Equation 2, $\mathbf{x}_{k}$ is the state of the system at instant $k$, vector $\mathbf{y}_{k}$ is the measured output vector, $\mathbf{w}_{k}$ is called process noise (containing the unmeasured inputs in addition to disturbances and model inaccuracies) and $\mathbf{v}_{k}$ is the output noise due to sensor inaccuracies.

The goal of the identification process is to estimate matrices $\mathbf{A}$ and $\mathbf{C}$, respectively called discrete state matrix and discrete output matrix, from a large number of measurements of output $\mathbf{y}_{k}$, since the eigenvalues and eigenvectors of these matrices are strictly correlated to the system's modal characteristics. The model order $n$ is twice the number of modes to be identified. A common procedure for SSI algorithms proceeds by evaluating matrices $\mathbf{A}$ and $\mathbf{C}$ for different modal orders. Modes that appear at many orders are considered stable. A plot of the natural frequencies vs. modal order is called the "stabilization diagram" and represents a powerful graphic tool to evaluate the modes identified by the algorithm [Rainieri and Fabbrocino 2014, Reynders et al. 2016]. The
SSI method is applied within a stochastic framework and also provides information on the uncertainties affecting the estimated values of the modal characteristics, due to both the errors in input modeling (colored input) and output measurements (instrumental noise).

Both the EFDD and the SSI/Cov methods have been applied to the data measured on the Maddalena Bridge [Azzara, De Falco et al. 2016]. In particular, while the EFDD method is implemented in TruDI, SSI/Cov method is implemented in the MACEC code [Reynders et al. 2014].

The results obtained are reported in Table 1, which shows the bridge's frequencies and modal damping ratios calculated for the five tests and for the first nine frequencies identified. Regarding the SSI/Cov method, the mean values of the frequency and damping ratios $\left(f_{S S I / C o v}\right.$ and $\left.\xi_{S S I / C o v}\right)$ are plotted, together with the corresponding standard deviations $\left(\sigma_{f}\right.$ and $\left.\sigma_{x}\right)$. Instead, the frequency and damping ratio values $\left(f_{E F D D}, \xi_{E F D D}\right)$ are reported for the EFDD method. All values in the table are related to mode shapes with Modal Phase Collinearity (MPC) greater than 0.85 . This parameter, ranging from 0 to 1 , quantifies the complexity of an eigenvector: MPC values near 1 indicate real vectors.

The table shows seven frequencies, ranging from 3.3 to $13.1 \mathrm{~Hz}$, that have been clearly identified on the bridge during the tests. The frequency values substantially coincide with those identified in the previous section via peak picking techniques. Frequencies $1(3.37 \mathrm{~Hz}), 2(5.06 \mathrm{~Hz})$, $4(7.06 \mathrm{~Hz})$, and $6(9.1 \mathrm{~Hz})$ have been identified with both methods (though not in every test, as detection depended on the sensor layout also). Frequency $3(5.4 \mathrm{~Hz})$ and frequency $5(8.8 \mathrm{~Hz})$, though present in the curves $\mathrm{s}_{\mathrm{i}}(\omega)$ of the singular values shown in Figure 10, are not as evident as the other frequencies, and hence have not been reported in Table 1 for the EFFD method. The eighth and ninth frequencies are present in the third test only, when the stations were placed on the bridge's parapets: as already observed in the previous section, they are clearly related to the free movements of the parapet walls. In particular, analysis of the single signals from Test 3 , as plotted in Figure 7, reveals that the ninth frequency (around 25 $\mathrm{Hz}$ ) is picked up only by the sensor in section $\mathrm{A}$, while the eighth (around $17 \mathrm{~Hz}$ ) is present in all the other sections. The bridge's frequencies have also been identified in Test 3 , thereby confirming the connection between the parapet and the bridge structure.

The uncertainties evaluated by the SSI/Cov method tend to increase for the high modes and for the tests involving sensor positions close to the roads (Tests 2 and 4). Moreover, the uncertainties related to the damping ra- 


\begin{tabular}{|c|c|c|c|c|c|c|}
\hline \multicolumn{7}{|c|}{ Frequency 1} \\
\hline TEST & $f_{\text {SSI } / \mathrm{Cov}[\mathrm{Hz}]}$ & $\sigma_{f[\mathrm{~Hz}]}$ & $f_{\mathrm{EFDD}[\mathrm{Hz}]}$ & $\xi_{\mathrm{SSI} / \mathrm{Cov} \%}$ & $\sigma_{\xi \%}$ & $\xi_{\text {EFDD } \%}$ \\
\hline 1 & 3.346 & \pm 0.007 & 3.349 & 2.69 & \pm 0.356 & 2.32 \\
\hline 2 & 3.378 & \pm 0.006 & 3.358 & 2.60 & \pm 0.168 & 3.28 \\
\hline 3 & 3.363 & \pm 0.006 & 3.372 & 2.63 & \pm 0.171 & 2.71 \\
\hline 4 & 3.374 & \pm 0.015 & 3.390 & 3.08 & \pm 0.436 & 3.97 \\
\hline 5 & 3.390 & \pm 0.039 & 3.403 & 3.05 & \pm 1.054 & 4.55 \\
\hline Av. & 3.370 & & 3.374 & 2.81 & & 3.37 \\
\hline \multicolumn{7}{|c|}{ Frequency 2} \\
\hline TEST & $f_{\mathrm{SSI} / \mathrm{Cov}[\mathrm{Hz}]}$ & $\sigma_{f[\mathrm{~Hz}]}$ & $f_{\mathrm{EFDD}[\mathrm{Hz}]}$ & $\xi_{\mathrm{SSI} / \mathrm{Cov} \%}$ & $\sigma_{\xi \%}$ & $\xi_{\text {EFDD } \%}$ \\
\hline 1 & 5.081 & \pm 0.034 & 5.123 & 4.05 & \pm 0.584 & 3.10 \\
\hline 2 & 5.100 & \pm 0.035 & 5.068 & 4.10 & \pm 0.625 & 3.53 \\
\hline 3 & 5.081 & \pm 0.023 & 5.136 & 3.59 & \pm 0.396 & 2.89 \\
\hline 4 & 4.989 & \pm 0.038 & 4.942 & 3.37 & \pm 1.395 & 4.43 \\
\hline 5 & 5.022 & \pm 0.023 & 5.046 & 3.97 & \pm 0.324 & 4.07 \\
\hline Av. & 5.055 & & 5.063 & 3.82 & & 3.60 \\
\hline \multicolumn{7}{|c|}{ Frequency 3} \\
\hline TEST & $f_{\mathrm{SSI} / \mathrm{Cov}[\mathrm{Hz}]}$ & $\sigma_{f[\mathrm{~Hz}]}$ & $f_{\mathrm{EFDD}[\mathrm{Hz}]}$ & $\xi_{\mathrm{SSI} / \mathrm{Cov} \%}$ & $\sigma_{\xi \%}$ & $\xi_{\mathrm{EFDD} \%}$ \\
\hline 1 & 5.346 & \pm 0.018 & - & 3.92 & \pm 0.295 & - \\
\hline 2 & 5.400 & \pm 0.017 & - & 2.30 & \pm 0.274 & - \\
\hline 3 & 5.361 & \pm 0.024 & - & 3.86 & \pm 0.411 & - \\
\hline 4 & - & - & - & - & - & - \\
\hline 5 & 5.493 & \pm 0.010 & - & 2.64 & \pm 0.316 & - \\
\hline Av. & 5.400 & & & 3.18 & & \\
\hline \multicolumn{7}{|c|}{ Frequency 4} \\
\hline TEST & $f_{\mathrm{SSI} / \mathrm{Cov}[\mathrm{Hz}]}$ & $\sigma_{f[\mathrm{~Hz}]}$ & $f_{\mathrm{EFDD}[\mathrm{Hz}]}$ & $\xi_{\text {SSI } / \text { Cov } \%}$ & $\sigma_{\xi \%}$ & $\xi_{\text {EFDD \% }}$ \\
\hline 1 & 7.033 & \pm 0.033 & 7.040 & 2.73 & \pm 0.271 & 2.76 \\
\hline 2 & 7.094 & \pm 0.064 & 7.101 & 2.22 & \pm 1.283 & 2.54 \\
\hline 3 & 7.090 & \pm 0.017 & 7.070 & 2.33 & \pm 0.177 & 2.10 \\
\hline 4 & 7.019 & \pm 0.058 & 7.106 & 3.43 & \pm 0.8 & 3.87 \\
\hline 5 & - & - & 7.009 & - & - & 2.74 \\
\hline Av. & 7.059 & & 7.065 & 2.68 & & 2.80 \\
\hline \multicolumn{7}{|c|}{ Frequency 5} \\
\hline TEST & $f_{\mathrm{SSI} / \mathrm{Cov}[\mathrm{Hz}]}$ & $\sigma_{f[\mathrm{~Hz}]}$ & EFDD $[\mathrm{Hz}]$ & $\xi_{\mathrm{SSI} / \mathrm{Cov} \%}$ & $\sigma_{\xi \%}$ & $\xi_{\text {EFDD } \%}$ \\
\hline 1 & 8.752 & \pm 0.059 & - & 2.34 & \pm 0.548 & - \\
\hline 2 & 8.812 & \pm 0.085 & - & 2.13 & \pm 0.459 & - \\
\hline 3 & 8.796 & \pm 0.075 & - & 1.22 & \pm 1.225 & - \\
\hline 4 & - & - & - & - & - & - \\
\hline 5 & 8.838 & \pm 0.094 & - & 2.90 & \pm 2.60 & - \\
\hline Av. & 8.800 & & & 2.15 & & \\
\hline \multicolumn{7}{|c|}{ Frequency 6} \\
\hline TEST & $f_{\mathrm{SSI} / \mathrm{Cov}[\mathrm{Hz}]}$ & $\sigma_{f[\mathrm{~Hz}]}$ & $f_{\mathrm{EFDD}[\mathrm{Hz}]}$ & $\xi_{\mathrm{SSI} / \mathrm{Cov} \%}$ & $\sigma_{\xi \%}$ & $\xi_{\mathrm{EFDD} \%}$ \\
\hline 1 & 9.121 & \pm 0.031 & 9.099 & 4.13 & \pm 0.514 & 2.48 \\
\hline 2 & 9.265 & \pm 0.064 & 9.149 & 3.60 & \pm 0.744 & 3.04 \\
\hline 3 & 9.171 & \pm 0.023 & 9.209 & 3.14 & \pm 0.313 & 2.38 \\
\hline 4 & - & - & - & - & - & - \\
\hline 5 & 9.188 & \pm 0.046 & 9.100 & 3.95 & \pm 0.705 & 3.27 \\
\hline Av. & 9.186 & & 9.139 & 3.71 & & 3.79 \\
\hline
\end{tabular}




\begin{tabular}{|c|c|c|c|c|c|c|}
\hline \multicolumn{7}{|c|}{ Frequency 7} \\
\hline TEST & $f_{\mathrm{SSI} / \mathrm{Cov}[\mathrm{Hz}]}$ & $\sigma_{f[\mathrm{~Hz}]}$ & $f_{\mathrm{EFDD}[\mathrm{Hz}]}$ & $\xi_{\mathrm{SSI} / \mathrm{Cov} \%}$ & $\sigma_{\xi \%}$ & $\xi_{\text {EFDD } \%}$ \\
\hline 1 & 13.101 & \pm 0.121 & 13.035 & 3.11 & \pm 1.487 & 3.25 \\
\hline 2 & 13.019 & \pm 0.074 & 12.878 & 3.24 & \pm 0.540 & 3.22 \\
\hline 3 & - & - & - & - & - & - \\
\hline 4 & - & - & - & - & - & - \\
\hline 5 & 13.011 & \pm 0.078 & 12.972 & 2.82 & \pm 0.658 & 3.31 \\
\hline Av. & 13.044 & & 12.962 & 3.00 & & 3.26 \\
\hline \multicolumn{7}{|c|}{ Frequency 8} \\
\hline TEST & $f_{\mathrm{SSI} / \mathrm{Cov}[\mathrm{Hz}]}$ & $\sigma_{f[\mathrm{~Hz}]}$ & $f_{\mathrm{EFDD}[\mathrm{Hz}]}$ & $\xi_{S S I / \text { Cov } \%}$ & $\sigma_{\xi \%}$ & $\xi_{\text {EFDD } \%}$ \\
\hline 1 & - & - & - & - & - & - \\
\hline 2 & - & - & - & - & - & - \\
\hline 3 & 17.577 & \pm 0.103 & - & 3.39 & \pm 0.60 & - \\
\hline 4 & - & - & - & - & - & - \\
\hline 5 & - & - & - & - & - & - \\
\hline \multicolumn{7}{|c|}{ Frequency 9} \\
\hline TEST & $f_{\mathrm{SSI} / \mathrm{Cov}[\mathrm{Hz}]}$ & $\sigma_{f[\mathrm{~Hz}]}$ & $f_{\mathrm{EFDD}[\mathrm{Hz}]}$ & $\xi_{\text {SSI } / \text { Cov } \%}$ & $\sigma_{\xi \%}$ & $\xi_{\text {EFDD } \%}$ \\
\hline 1 & - & - & - & - & - & - \\
\hline 2 & - & - & - & - & - & - \\
\hline 3 & - & - & 25.144 & - & - & 1.570 \\
\hline 4 & - & - & - & - & - & - \\
\hline 5 & - & - & - & - & - & - \\
\hline
\end{tabular}

Table 1. Natural frequencies and modal damping ratios evaluated via the SSI/Cov and the EFDD methods.

tios are generally much higher than those related to the frequencies. With regard to damping, the values of the modal damping ratios calculated in the various tests and for each method tend to appear quite dispersed. However, comparison (Table 1) between the averaged (over the five tests) damping ratios calculated for the two methods reveals differences of less than twenty-five percent, which is, in the authors' opinion, quite an acceptable value.

Figure 9 shows the diagram for Test 1 plotted via the MACEC code (SSI/Cov method). Figure 10 shows the singular values decomposition of the spectral density matrices calculated by TruDI (EFDD method) for Test 1. The highlighted peaks represent the identified natural frequencies of the structure.

Finally, Figures 11 and 12 show the first six ap-

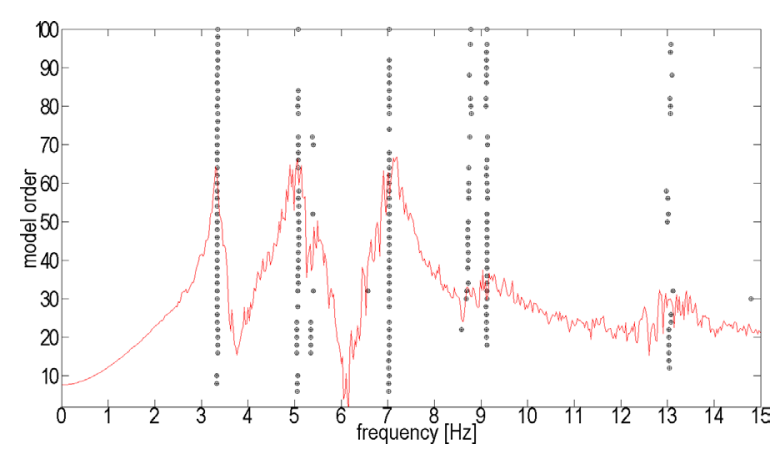

Figure 9. Stabilization diagram for Test 1. proximate mode shapes of the bridge (corresponding to the first six frequencies identified), plotted via the TruDI code. The results have been obtained by suitably combining the data from Tests 1, 2, 4 and 5 and taking Section $\mathrm{D}$ as reference node. For the modes not identified by the EFDD method (mode shapes 3 and 5), the eigenvector calculated by MACEC has been imported and plotted in TruDI. Mode shape 1 refers mainly to out-of-plane motions of the bridge, while Mode shapes 2, 4 and 6 refer to in-plane motions. In particular, Mode 6 presents the classical anti-symmetric geometry of the arches' in-plane vibrations, while Mode shape 4 seems to represent a pure in-plane motion of the entire structure, with clearly evident longitudinal deformations. Mode shapes 3 and 5 are less

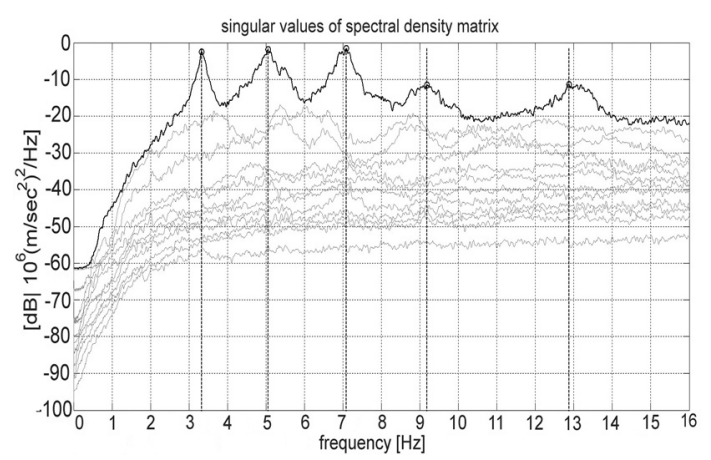

Figure 10. Singular value decomposition of spectral density matrices of Test 1 (EFDD technique). The peaks are highlighted. 


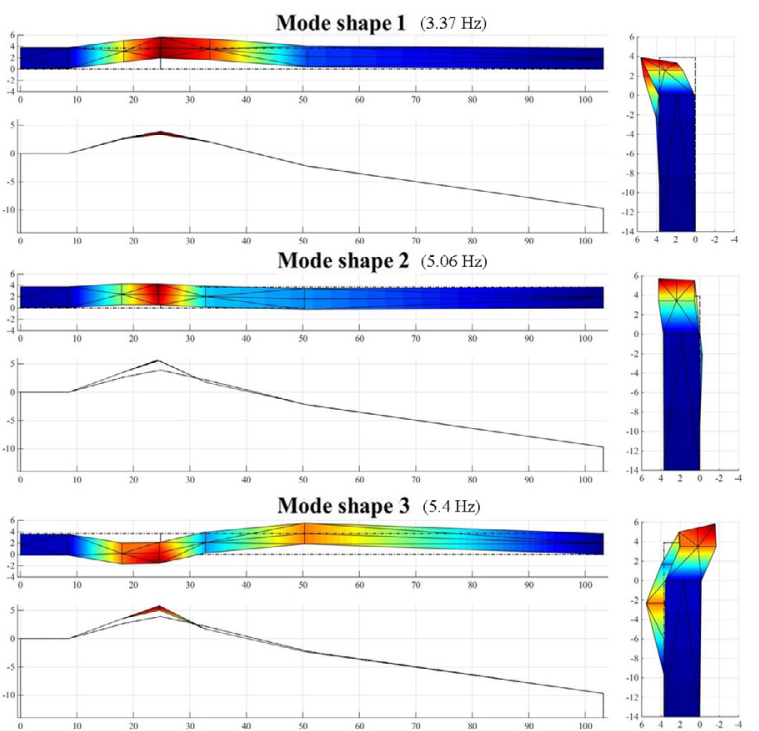

Figure 11. The first three mode shapes of the bridge evaluated experimentally: plane, frontal and lateral views. The gray line represents the undeformed shape.

well defined: mode shape 3 represents an anti-symmetric out-of-plane mode shape, and mode shape 5 is also out-of-plane, with a considerable torsional component. Moreover, torsional movements have been identified in all mode shapes and can be considered a consequence of the bridge's irregular geometry.

\subsection{A finite-element model for the Maddalena Bridge}

The Maddalena Bridge has been discretized into three-dimensional finite elements via the NOSA-ITACA code [Binante et al. 2017], a finite-element code which is freely distributed by the Mechanics of Materials and Structures Laboratory of ISTI-CNR. The bridge model [De Falco et al. 2014] is shown in Figure 13.

The mesh consists of 41954 8-node brick elements with linear interpolation functions, and 52206 nodes, for a total of 156618 degrees of freedom. The boundary conditions assigned to the bridge are also specified in the figure. In particular, the base nodes of the piers have been constrained in the $z$ direction by linear elastic springs. In addition, in order to simulate the effect of the railway embankment close to the bridge structure, the nodes in the proximity of the railway have been restrained in the $x$ and $y$ directions, while the lateral nodes in the proximity of the left shore have been restrained in the $x$ direction in order to take into account the presence of the soil on the river bank.

With regard to the constituent materials, some sonic tests were performed at the extrados of the bridge in correspondence to the central pier [Gucci and De Falco 2010]. This was a seismic refraction survey performed by deploying on the stone pavement

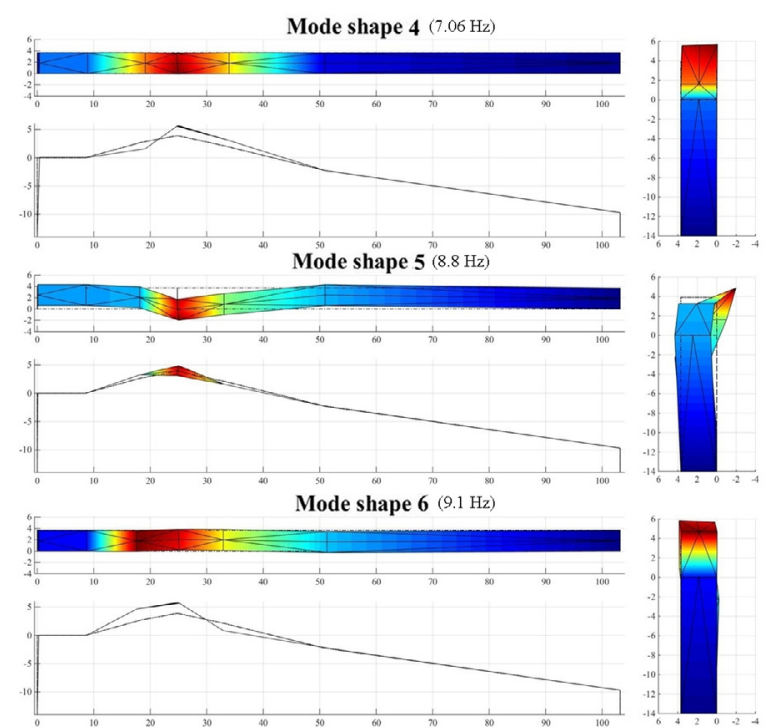

Figure 12. The fourth, fifth and sixth mode shapes of the bridge evaluated experimentally: plane, frontal and lateral views. The grey line represents the undeformed shape.

24 geophones in a row with about one meter spacing, and striking a steel plate resting on the surface with a hammer. These tests yielded an average velocity of about $1500 \mathrm{~m} / \mathrm{s}$ within the infill masonry, just three meters below the pavement. The corresponding value of the material's Young's modulus is about 4200 $\mathrm{MPa}$ for a density of $2000 \mathrm{~kg} / \mathrm{mc}$. The wave velocity increases downward, starting from the extrados of the bridge. These quite high values demonstrate the good mechanical quality of the infill. No in situ tests were performed on the external masonry due to the difficulty of reaching the surface submerged in the water of the reservoir. Nevertheless, upon visual inspection the external layer appears to be made up of massive limestone and sandstone masonry (see Figure 3) with very thin mortar joints. Macigno sandstone

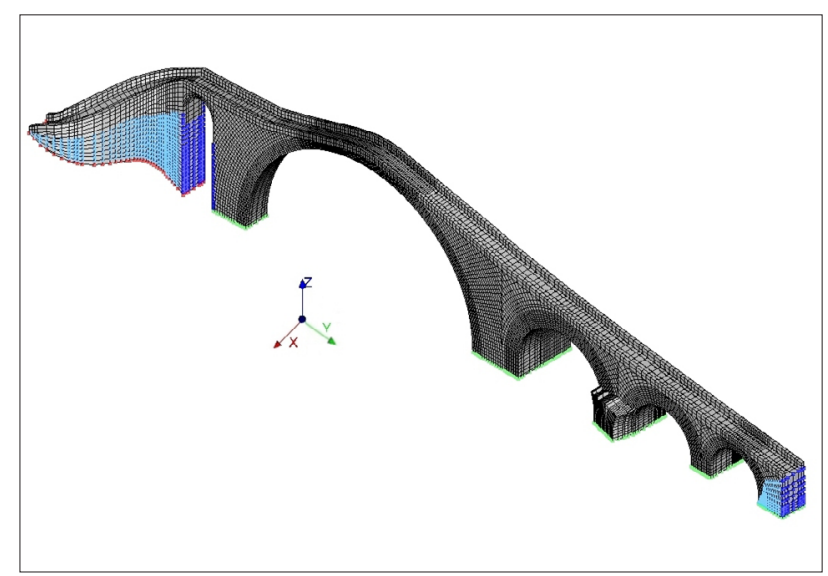

Figure 13. Finite-element model of the Maddalena Bridge. Blue dots: fixed displacements in the $x y$ plane; cyan dots: fixed displacements along $x$; red dots: fixed displacements in the three directions; green dots: linear elastic springs along $z$ and fixed displacements in the $x y$ plane. 
has always been widely used as a building material in the Garfagnana and Lunigiana areas (surrounding the bridge) [Franzini et al. 2007], [Lezzerini et al. 2008]. Its mechanical properties can be deduced from the scientific literature; in particular, the Macigno Formation (from Upper Oligocene to Lower Miocene) cropping out extensively in the Northern Apennines consists of grey to bluish-grey, well-consolidated siliciclastic sandstones, with quartz, feldspar and micas [Cantisani et al. 2013]. They are characterized by low values of both porosity and water absorption at atmospheric pressure, low susceptibility to freeze-thaw cycles, and high compressive strength. Its compressive strength exhibits anisotropic behavior, ranging from $100 \mathrm{MPa}$ to 140 MPa [Cantisani et al. 2013] [Lezzerini et al. 2008], with significant differences related to the load directions perpendicular and parallel to the quarry bed.

With regard to the parapet walls, the dynam- proximation was achieved between the numerical and experimental values of the bridge's dynamic characteristics. A solution to this optimization problem has been found by considering a homogeneous material with average mass density of $20 \mathrm{kN} / \mathrm{m}^{3}$ and Young's modulus of $6500 \mathrm{MPa}$. The high resulting value of the homogenized Young's modulus should be regarded as an initial, dynamic value of high quality masonry. It takes into account the overall composition of the bridge's section, whose internal geometry is at present unknown. With regard to the deformability of the foundation soil, two different stiffness values have been considered for the right and left parts of the river bank, which correspond to very compact cohesive soil and rock, respectively [Bowles 2001].

Table 2 shows the first six bridge fundamental frequencies evaluated via the finite-element code $\left(f_{\mathrm{FEM}}\right)$ vs. the experimental values $\mathrm{f}_{\mathrm{EXP}}$ (average of $\mathrm{SSI}_{/ \mathrm{Cov}}$

\begin{tabular}{lcccccc}
\hline & $f_{\mathrm{FEM}}[\mathrm{Hz}]$ & $f_{\exp }[\mathrm{Hz}]$ & $\begin{array}{c}\left(f_{\mathrm{FEM}}-f_{\exp }\right) / f_{\text {exp }} \\
{[\%]}\end{array}$ & $\begin{array}{c}\mathrm{U}_{\mathrm{X}} \\
{[\%]}\end{array}$ & $\begin{array}{c}\mathrm{U}_{\mathrm{Y}} \\
{[\%]}\end{array}$ & $\begin{array}{c}\mathrm{U}_{\mathrm{Z}} \\
{[\%]}\end{array}$ \\
\hline Mode shape 1 & 3.20 & 3.37 & -5.04 & 20.56 & 0.04 & 0.08 \\
Mode shape 2 & 5.13 & 5.06 & 1.58 & 0.03 & 1.58 & 18.45 \\
Mode shape 3 & 5.48 & 5.40 & 1.48 & 5.95 & 0.01 & 0.29 \\
Mode shape 4 & 7.17 & 7.06 & 1.56 & 1.77 & 22.12 & 4.61 \\
Mode shape 5 & 8.47 & 8.80 & -3.75 & 0.53 & 0.71 & 0.00 \\
Mode shape 6 & 9.54 & 9.19 & 3.81 & 0.00 & 0.33 & 2.92 \\
Mode shape 8 & 17.50 & 17.60 & -0.57 & 0.16 & 0.00 & 3.96 \\
\hline
\end{tabular}

Table 2. Bridge's fundamental frequencies evaluated by the finite-element code $\left(\mathrm{f}_{\mathrm{FEM}}\right)$ vs. experimental values $\left(\mathrm{f}_{\exp }\right)$.

ic tests showed a good connection with the bridge's structure, as described in previous sections. For this reason, they have been modeled in detail in the finite-element mesh. As no information is available on their mechanical properties, a rough identification was first performed using the out-of-plane vibration frequency of the parapet measured in Test 3, about 17 $\mathrm{Hz}$. Thus, we have considered a cantilever beam with rectangular section of unit length and thickness of $0.4 \mathrm{~m}$. If the specific weight of the masonry is taken to be about $20 \mathrm{kN} / \mathrm{m}^{3}$, then the value of the material's Young's modulus that would yield a fundamental beam frequency of $17.6 \mathrm{~Hz}$ is $3800 \mathrm{MPa}$. Therefore, these values have been entered in the finite-element model for the mechanical properties of the parapet walls.

The three-dimensional finite-element model has been updated by varying the mechanical properties of the bridge's constituent materials and the stiffness of the springs at the base of the piers until a good ap- values). A very good correspondence can be seen between the numerical and experimental results: the relative differences are lower than $5 \%$. Mode shape 8 has also been identified in the FE model and is reported in the table. The values of the modal participating masses calculated by the NOSA-ITACA code in the three directions are also reported (expressed as percentages of the bridge's total mass). They substantially agree with the experimental results: the first and third mode shapes represent out-of-plane motions, the second and the sixth are in the plane $y-z$ with movements in the vertical direction, the fourth, again in-plane, exhibits large longitudinal movements. It is worth noting that the third, fifth and eighth mode shapes, which were detected by the SSI / CoV algorithm only, involve small percentages of the bridge's total mass.

Figures 14 and 15 plot the bridge's mode shapes, as calculated by the NOSA-ITACA code. The good correspondence between the numerical modes and those evaluated via experimental data is evident (Figures 11 


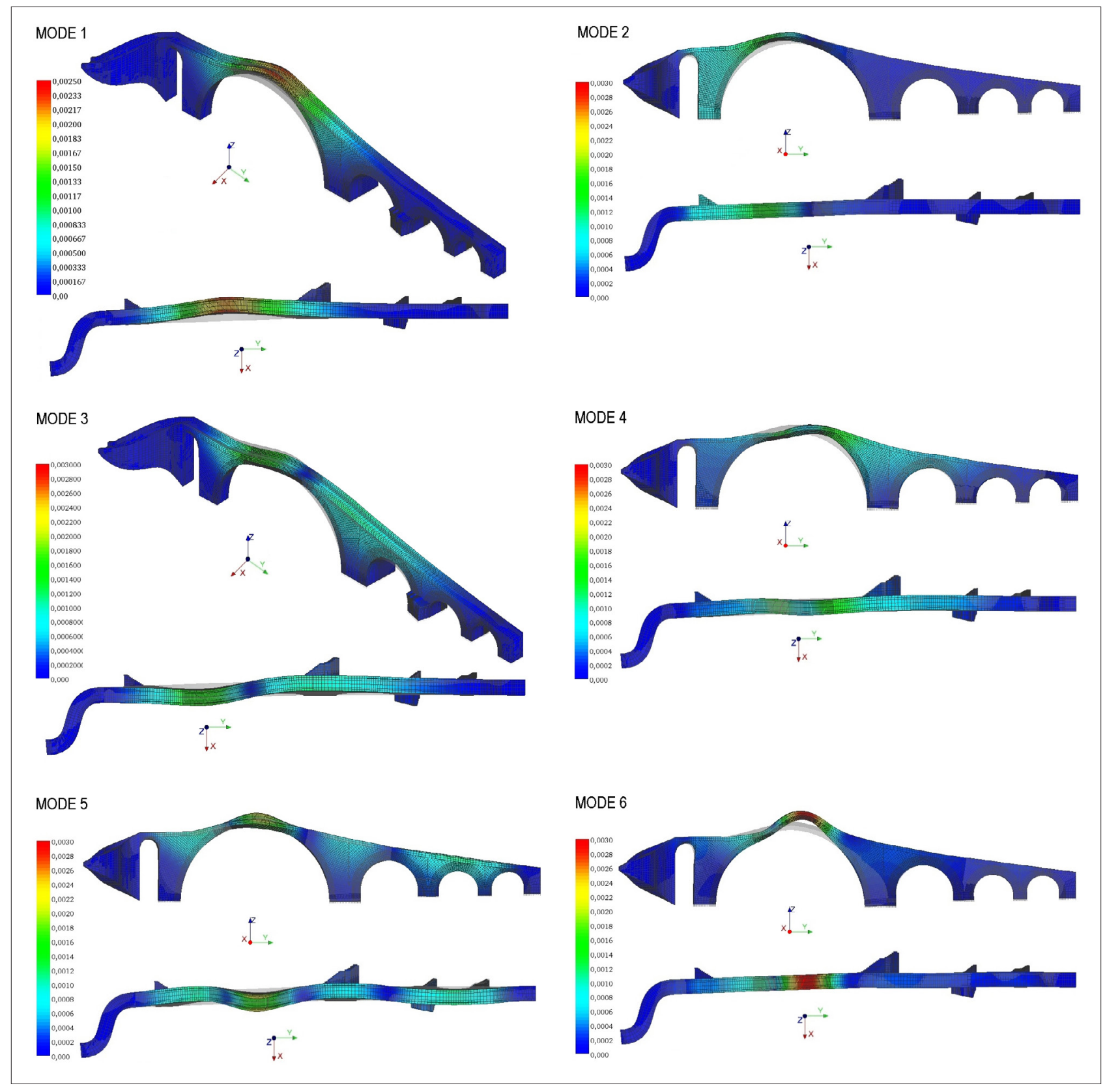

Figure 14. The bridge's first six mode shapes calculated via the NOSA-ITACA code.

and 12). The eighth mode shape $(17.5 \mathrm{~Hz})$, evaluated by the finite-element code (Figure 15), mainly involves out-of-plane movements of the parapet walls, thus confirming the experimental results.

\section{Conclusions}

The paper presents the results of a vibration monitoring campaign recently conducted on the Maddalena Bridge (Devil's Bridge) in Borgo a Mozzano (Lucca, Italy). The monument was instrumented with four three-axial seismometers, which were left active on the bridge for several hours. A preliminary analysis was first performed on the signals to obtain a rough evaluation of the bridge's natural frequencies. Then, the data have been processed in the time domain via the Covariance-driven Stochastic Subspace Identification method, implemented in the MACEC code and in the frequency domain via the Enhanced Frequency Domain Decomposition method, implemented in the TruDI code. The bridge's natural frequencies, mode shapes and damping ratios have been calculated for different arrangements of the sensors on the bridge and are reported in the paper. During the experimentation the sensors were also moved from the bridge's extrados to the top of the bridge's parapets, thus enabling us to identify the degree of connection between the parapets and the bridge structure proper.

A three-dimensional FE model of the bridge has enabled us to estimate the main mechanical properties of the bridge's constituent materials and characterize 


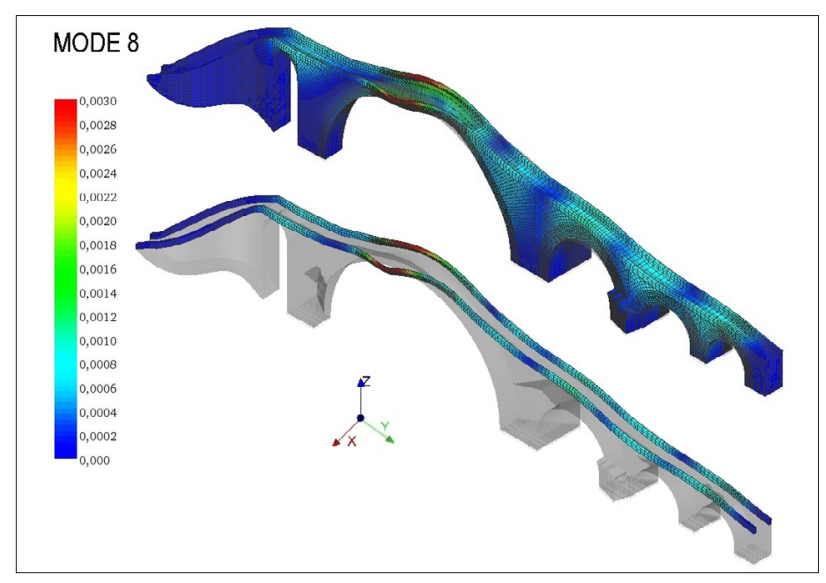

Figure 15. The eighth mode shape calculated via the NOSA-ITACA code.

the boundary conditions involved. A very good correspondence has been found between six values of the experimental and numerical frequencies.

The paper confirms that the use of peak-picking is the basis of system identification and can provide important information. Other algorithms like those presented in the paper enable taking into account all the signals measured simultaneously on the structure and the geometry of the sensor network, thereby providing for estimation not only of the frequencies, but the mode shapes and modal damping ratios as well.

In conclusion, this expeditious experimental campaign has yielded a good deal of significant information on the bridge and enhanced our knowledge of this remarkable structure.

Acknowledgements. This research has been partially funded by the "Fondazione Cassa di Risparmio di Lucca" (Project TITANIO) and the Region of Tuscany (FAR-FAS 2014, Project MOSCARDO). Such support is gratefully acknowledged.

\section{References}

Aoki, T., Sabia D., Rivella, D.and Komiyama, T. R. 2007. Structural Characterization of a stone arch bridge by experimental tests and numerical model updating. International Journal of Architectural Heritage: Conservation, Analysis and Restoration. 1(3): 227-250.

Azzara, R.M., De Falco, A., Girardi, M., Pellegrini, D., 2016. Measurement of the vibration response of the medieval Maddalena Bridge (Italy), Proceedings of the Tenth International Conference on Structural Analysis of Historical Constructions, Leuven, 1315 September 2016.

Azzara, R.M., De Roeck G., Girardi, M., Padovani, C., Pellegrini, D. and Reynders, E., 2016. Assessment of the dynamic behaviour of an ancient masonry tower in Lucca via ambient vibrations, Proceedings of the Tenth International Conference on Structural Analysis of Historical Constructions, Leuven, 1315 September 2016.

Azzara, R.M., Zaccarelli, L., Morelli, A., Trombetti, T., Dallavalle G., Cavaliere A. and Danesi S. 2014. Seismic monitoring of the Asinelli and Garisenda medioeval towers in Bologna (Italy), an instrumental contribution to the engineering modeling direct to their protection. In F. M. Mazzolani and G. Altay (eds.), Proceedings of the second International Conference on Protection of Historical Constructions (PROHITECH 2014). Proc. intern. symp., Antalya, Turkey, May 7-9 2014. Istanbul: Boğaziçi University Publishing.

Batel, M. 2002. Operational Modal Analysis - Another Way of Doing Modal Testing. Sound and Vibration. 36(8): 22-27.

Bayraktar, A., Birinci, F., Altunısık, A.C., Türker, T. and Sevim, B. 2009. Finite element model updating of Senyuva historical arch bridge using ambient vibration tests. Baltic J Road Bridge Eng. 4(4):177-85.

Bayraktar, A., Turker, T. and Altunisik, C.A. 2015. Experi-mental frequencies and damping ratios for historical masonry arch bridges. Construction and Building Materials. 75:234-241.

Binante V., Girardi M., Padovani C., Pasquinelli G., Pellegrini D., Porcelli M., Robol L. 2017. NOSA-ITACA documentation. Version 1.1. www.nosaitaca.it.

Boscato, G., Tommaso, A.D., Guerra, F., Lazzarini, L., Maz-zucato, A., Pizzolato, M., et al. 2010. Approach and methodology in understanding the structural behaviour of historic arch bridges through dynamic monitoring: the case of Rialto bridge in Venice. In A. Steffen (ed.) Proceedings of the 34th IABSE symposium on large structures and infrastructures for environmentally constrained and urbanised areas; Proc. intern. symp., Venice, Italy, September 22-24, 2010. Zürich: International Association for Bridge and Structural Engineering.

Bowles J.E. Foundation analysis and design. 2001. McGrow-Hill International Book Company.

Brincker, R., Ventura, C. and Andersen, P., 2001, Damping estimation by frequency domain decomposition, Proceedings of the 19th International Modal Analysis Conference (IMAC).

Brincker, R. and Ventura, C., 2015, Introduction to Operational Modal analysis, Wiley.

Cantisani, E., Garzonio, C.A., Ricci, M., and Vettori S. 2013. Relationships between the petrographical, physical and mechanical properties of some Italian sandstones. International Journal of Rock Mechan- 
ics and Mining Sciences, 60:321-332.

De Falco, A., Girardi, M. and Pellegrini, D. 2014. Non-Linear Analyses on the Medieval "Ponte del Diavolo" in Borgo a Mozzano (Italy). In B.H.V. Topping and P. Iványi, (eds), Twelfth International Conference on Computational Structures Technology; Proc. intern. symp., Naples, 2-5 September 2014. Edinburgh, UK: Civil-Comp Press.

Franzini, M., Leoni L., Lezzerini M. and Cardelli R. 2007 - Relationships between mineralogical composition, water absorption and hydric dilatation in the "Macigno" sandstones from Lunigiana (Massa, Tuscany). Eur. J. Mineral., 19:113-123.

Gioffrè, M., Gusella, V. \& Cluni, F. 2008. Performance evaluation of monumental bridges: testing and monitoring 'Ponte delle Torri' in Spoleto. Structure and Infrastructure Engineering. 4(2):95-106.

Gucci, N. and De Falco, A., 2010. Il Fascino e la Funzione, il Ponte della Maddalena detto del diavolo. Lucca: Pacini Fazzi Editore.

Lezzerini, M., Franzini, M., Di Battistini, G. and Zucchi D. 2008. The "Macigno" sandstone from Matraia and Pian di Lanzola quarries (North-Western Tuscany, Italy). A comparison of physical and mechanical properties. Atti Soc. tosc. Sci. nat., Mem., Serie A, 113:71-79.

Pellegrini, D. 2015. TruDI - A Matlab toolbox for structural dynamic identification. Software n. 2015-SW024, http: / / pumalab.isti.cnr.it/index.php/it.

Pérez-Gracia, V., Di Capua, D., Caselles, O., Rial, F., Lorenzo, H., Gonzalez-Drigo, R. \& Armesto, J. 2011. Characterization of a Romanesque Bridge in Galicia (Spain), International Journal of Architectural Heritage: Conservation, Analysis and Restoration. 5(3), 251-263.

Rainieri, C. and Fabbrocino, G. 2014. Operational Modal Analysis of Civil Engineering Structures. An Introduction and Guide for Applications. New York: Springer Science + Business Media.

Reynders, E., Schevenels, M. and De Roeck, G., 2014. MACEC 3.3. A Matlab toolbox for experimental and operational modal analysis. http:/ / bwk.kuleuven.be/bwm/macec/.

Reynders, E., Maes, K., Lombaert, G. and De Roeck, G. 2016. Uncertainty quantification in operational modal analysis with stochastic subspace identification: Validation and applications. Mech. Syst. Signal Process 66-67:13-30.

Sevim, B., Bayraktar, A., Altunısık, A.C., Atamtürktür, S. and Birinci, F. 2011. Finite element model calibration effects on the earthquake response of masonry arch bridges. Finite Elem Anal. Des. 47(7):621-34.

Weale, J., Hann, J., Hosking, W., Stevenson, R., Moseley, H., Hughes, T.and Hill L. 1843. The Theory, Practice, and Architecture of Bridges of Stone, Iron, Timber, and Wire: With Examples on the Priciples of Suspension, Vol. 2 printed by W. Hughes, King's Head Court, Gough Square, London.

\footnotetext{
*Corresponding author: Riccardo M. Azzara, Istituto Nazionale di Geofisica e Vulcanologia, Osservatorio Sismologico di Arezzo, Arezzo, Italy; email: riccardo.azzara@ingv.it (C)2017 by Istituto Nazionale di Geofisica e Vulcanologia. All rights reserved
} 